\title{
PERANCANGAN BRAND VISUAL IDENTITY WISATA CERDAS KABUPATEN KERINCI
}

\author{
Rizky Alfadly ${ }^{1}$, Yosa Fiandra ${ }^{2}$ \\ Program Pascasarjana ${ }^{1,2}$ \\ Program Studi Desain Komunikasi Visual, Institut Seni Indonesia Padang Panjang ${ }^{1}$ \\ Program Studi Desain Komunikasi Visual, Telkom University ${ }^{2}$ \\ rizkyalfadly49@gmail.com ${ }^{1}$ \\ pichaq@telkomuniversity.ac.id ${ }^{2}$
}

\begin{abstract}
Abstrak
Sektor Pariwisata menjadi sangat penting untuk diperhatikan guna menunjang peningkatan kualitas hidup bagi daerah tujuan wisata. Kabupaten Kerinci dikenal sebagai surganya Pariwisata Provinsi Jambi, hampir 75\% objek wisata di Provinsi Jambi berada di Kabupaten Kerinci, hal ini sekaligus menjadikan Kabupaten Kerinci sebagai Branding Pariwisata Provinsi Jambi. Namun dengan demikian penetapan Kabupaten Kerinci sebagai branding Pariwisata Provinsi Jambi belum disertai dengan peningkatan kualitas pengelolaan pengembangan pariwisata. Terutama pada disiplin ilmu Brand Visual Identity yang dewasa ini tengah mengalami perkembangan trend yang sangat pesat di berbagai wilayah di Indonesia maupun negara di dunia. Perancangan Brand Visual Identity ini bertujuan untuk menaikkan popularitas pariwisata Kabupaten Kerinci agar lebih dikenal dan sekaligus menjadikan daya tarik bagi para wisatawan lokal, regional, nasional, maupun internasional. Perancangan ini menggunakan metode 4D (Define, Design, Develop, and Disseminate). Tahap pertama dengan mencari sebanyak mungkin definisi-definisi istilah yang akan digunakan dalam perancangan untuk menambah wawasan perancang, lalu melakukan teknis perancangan, dengan menggunakan media manual dan digital, setelah itu dikembangkan menjadi beberapa alternatif pilihan agar sesuai dengan apa yang dikehendaki target sasaran, dan yang terakhir tahap penyebar luasan atau publishing. Tahap ini bisa menggunakan media offline (media luar ruang) maupun media online (web, aplikasi, dan media sosial). Capaian dari perancangan ini supaya Kabupaten Kerinci relevan sebagai penyandang Branding Pariwisata Provinsi Jambi.
\end{abstract}

Kata Kunci : Brand Visual Identity - Wisata Cerdas - Kabupaten Kerinci

\section{Abstract}

The Tourism sector is very important to pay attention to in order support the improvement of the quality of life for tourist destinations. Kerinci Regency is known as the tourism paradise of Jambi Province, almost 75\% of tourism objects in Jambi Province are located in Kerinci Regency, this also makes Kerinci Regency a tourism branding for Jambi Province. However, the determination of the Kerinci Regency as the Tourism branding of Jambi Province has not been accompanied by an increase in the quality of tourism development management. Especially in the dicipline of Brand Visual Identity, which is currently experiencing a very rapid trend development in various regions in Indonesia and Countries in the world. The design of this Brand Visual identity aims to increase the popularity of tourism in Kerinci Regency so that it is better known and at same time makes it an attraction for local, regional, nasional, and international tourists. This design uses the 4D method (Define, Design, Development, and Disseminate). The first stage is to find as many definitions of terms that will be used in the design to add to the designers insight, then carry out technical design, using manual and digital media, after which it it developed into several alternative choices so that they are rational with what the target audience wants. The last stage is the distribution or publishing. This stage can use offline media (outdoor media) and online media (web, application, and social media). The achievement of this design is so that Kerinci Regency is relevant as a provider of Jambi Province Tourism Branding.

Keywords : Brand Visual Identity - Smart Tourism - Kerinci Regency

\section{PENDAHULUAN}

Kabupaten Kerinci dikenal dengan julukan Sekepal Tanah Surga Sakti Alam Kerinci. Julukan ini merupakan representasi dari banyaknya jumlah objek pariwisata yang terdapat di wilayah tersebut. Kabupaten Kerinci memiliki berbagai jenis wisata. diantaranya, wisata alam, wisata budaya, wisata religi, dan juga wisata sejarah.

Tahun 2016 lalu Kabupaten Kerinci mendapat anugerah sebagai Branding Pariwisata Provinsi Jambi, tentu saja dengan sangat mudah Kabupaten Kerinci mendapatkan penghargaan tersebut, karena secara kuantitas jelas Kerinci memiliki jumlah objek pariwisata yang sangat banyak dibanding Kabupaten lainnya di Provinsi Jambi, Adirozal (Bupati Kerinci) menegaskan bahwasanya ada sekitar 75 destinasi wisata yang berada di Kabupaten Kerinci [1].

Kabupaten Kerinci dengan beragam keindahan alam dan budaya yang menarik yang saat ini masih belum menunjukkan eksistensinya secara global kepada khalayak ramai. Sebagai daerah pariwisata yang sangat potensial, daerah ini juga dikenal dengan istilah "3Ter" yang memiliki Gunung Kerinci sebagai gunung Ter-tinggi di Sumatera (Top of Sumatera), Danau Gunung Tujuh sebagai danau vulkanik Ter-tinggi se-Asia Tenggara, serta perkebunan Teh Kayu Aro merupakan perkebunan kebun teh Ter-luas se-Asia Tenggara[2].

Jenis pariwisata yang terdapat di kabupaten Kerinci saat ini dinilai sangat komplit, mulai dari wisata alam, wisata budaya, wisata sejarah, wisata religi, serta wisata buatan. Namun dengan demikian, penetapan Kabupaten Kerinci sebagai branding pariwisata Provinsi Jambi belum disertai dengan peningkatan kualitas pengelolaan pengembangan pariwisata sebagaimana mestinya diharapkan. Masih terdapat banyak fenomena-fenomena yang menjadikan citra pariwisata Kabupaten Kerinci susah untuk muncul ke ruang lingkup yang lebih luas. 
Perancangan Brand Visual Identity Wisata cerdas Kabupaten Kerinci sangatlah perlu diterapkan untuk menunjang keberhasilan Kabupaten Kerinci yang tengah menyandang predikat sebagai Branding Pariwisata Provinsi Jambi.

Desain Komunikasi Visual hadir sebagai salah satu solusi komunikasi melalui serangkaian pertimbangan dan realisasi dengan diciptakannya media-media komunikasi, khususnya media komunikasi visual agar tujuan komunikasi tercapai secara maksimal[3].

Branding Pariwisata akhir-akhir ini sangat popular. Berbagai kota ataupun wilayah pariwisata tengah berlomba-lomba untuk meningkatkan brand nya masing-masing. Dibutuhkan visual komuniasi yang berlandaskan pada nilai-nilai estetis, etis, dan logis untuk mempromosikan Pariwisata Kabupaten Kerinci ke kancah nasional maupun internasional.

Adapun media dan gagasan yang dirancang nantinya untuk mewujudkan wisata cerdas Kabupaten Kerinci ialah berupa Identitas Visual Brand Pariwisata Kabupaten Kerinci berbasis pada konsep wisata cerdas yang ingin direalisasikan.

\section{KAJIAN TEORI}

1. Identitas Visual

Identitas visual adalah identitas yang berkaitan dengan citra atau pemikiran yang dipertahankan oleh perusahaan sebagai salah satu cara untuk menyatukan berbagai konteks bagi perusahaan tersebut. Ciri khas yang mengandung sesuatu yang menghasilkan sebuah perbedaan dan mewakili citra sebuah organisasi. 16 Identitas dapat berasal dari sejarah, filosofi, visi atau cita-cita, misi atau fungsi, tujuan, maupun sebuah program. Unsur dari seebuah identitas terdiri dari nama perusahaan, logo, slogan, maskot, sistem grafis, elemen visual, media aplikasi resmi (official) serta media pendukung dan promosi (komersial)[4]. Dapat disimpulkan bahwa Identitas visual merupakan sebuah ungkapan ekspresi dan identitas suatu produk yang dihasilkan dari perusahaan tersebut, identitas visual merupakan ciri khas yang hanya dimiliki perusahaan, agar suatu perusahaan mudah dikenal dan mendapat kepercayaan dari masyarakat sebagai calon konsumen.

\section{Branding}

Branding berasal dari kata brand yang memiliki arti merek. Menurut Wirania Swasty dalam bukunya yang berjudul Branding memahami dan merancang strategi merek terbitan [5]. Mengatakan bahwa branding adalah suatu program yang mengkhususkan atau memfokuskan dan memproyeksikan nilai-nilai merek. Program ini meliputi penciptaan perbedaan antara produk dan pelanggan dalam proses pengambilan keputusan pembeli serta pemberian nilai-nilai pada perusahaan. Jadi branding merupakan keseluruhan proses dalam memilih unsur, nilai hingga janji apa yang dimiliki oleh suatu entitas (produk, jasa, perusahaan. Branding adalah proses disiplin yang digunakan untuk membangun kesadaran dan memperluas loyalitas pelanggan.

Penulis dapat menyimpulkan bahwa Branding merupakan sebuah kata yang dapat menyimpulkan suatu bentuk cara dalam menggambarkan atau memperkuat suatu merek produk ataupun jasa. Dan membedakannya dengan yang lain. Unsur-unsur yang mempengaruhi kekuatan sebuah merek adalah, dari apa yang anda lihat (tangible), dan dari apa yang anda dengar dan yang anda rasakan (intangible). Kedua unsur tersebut merupakan syarat utama dalam membangun kekuatan merek pada kompetisi pasar. Elemen-elemen yang terdapat dalam kedua unsur tersebut adalah sebagai berikut:

1. Tangible: Produk, Packagingkemasan, identitas visual, dsb.

2. Intangible: Kualitas produk dan jasa.

\section{3. $\log 0$}

Logo, berasal dari bahasa Yunani yaitu logos, yang berarti pikiran, pembicaraan, akal budi. Pada awalnya yang lebih populer adalah istilah logotype, berbeda dengan logo. Pertama kali istilah logotype muncul tahun 1810-1840, yang diartikan sebagai tulisan nama entitas desain secara khusus dengan menggunakan teknik lettering atau memakai jenis huruf tertentu logotype adalah elemen tulisan saja[6]. Logo merupakan suatu hal yang nyata dan dapat menjadi sebuah pencerminan hal-hal yang bersifat non visual dari suatu perusahaan, misalnya sikap, kepribadian, yang dituangkan dalam bentuk [7]. Sedangkan menurut Rustan [8] logo bisa dikatakan sebagai arti lain dari kata logotype. Istilah logo baru muncul tahun 1937 dan kini istilah logo lebih banyak dikenal daripada logotype. Logo juga dianggap sebagai elemen gambar atau simbol pada identitas visual.

\section{Pariwisata}

Istilah pariwisata berasal dari dua suku kata, yaitu pari dan wisata. Pari berarti banyak, berkali-kali atau berputarputar. Wisata berarti perjalanan atau bepergian. Jadi pariwisata adalah perjalanan yang dilakukan berkali-kali atau 
berputar-putar dari suatu tempat ke tempat yang lain. Pariwisata merupakan salah satu factor penting dalam perkembangan perekonomian Indonesia. Hal ini karena pariwisata merupakan ujung tombak dari kemajuan perekonomian suatu negara. Pariwisata biasanya menarik investor asing yang dibutuhkan oleh setiap negara yang sedang berkembang. Pariwisata juga mempunyai tanggung jawab untuk membawa nama atau citra suatu bangsa agar dikenal di dunia internasional. Semakin berkualitas pelayanan pariwisata di suatu negara atau di suatu daerah maka negara atau daerah tersebut semakin berkembang dan semakin dikenal. Seiring dengan perkembangan di berbagai bidang seperti politik, ekonomi, social, dan budaya. Pariwisata juga mempunyai peran penting dalam perkembangannya. Sektor pariwisata Indonesia merupakan penyumbang devisa yang signifikan. Secara keseluruhan, sector pariwisata menjadi penyumbang no 5 (tahun 2008), no 4 (tahun 2009), dan no 5 (tahun 2010). Jika dilihat dari sector non-migas, pariwisata menempati urutan ke 2 atau 3. Pariwisata juga menjadi sumber penyedia lapangan kerja terbesar.

Dalam berbagai forum diskusi yang diselenggarakan oleh Kementerian Kebudayaan dan Pariwisata (sekarang: Kementerian Pariwisata dan Ekonomi Kreatif) untuk mendiskusikan adopsi etos dan prinsip pemasaran pariwisata yang bertanggung jawab, didapatkanlah kesan bahwa pemasaran pariwisata yang bertanggung jawab dipandang sebagai suatu cita-cita utopis [9].

\section{Kabupaten Kerinci}

Kabupaten Kerinci merupakan salah satu Kabupaten yang berada di Provinsi Jambi. Kabupaten Kerinci juga suatu wilayah yang memiliki beragam keindahan alam dan budaya yang menarik yang belum banyak diketahui khalayak. Kabupaten Kerinci memiliki slogan daerah yaitu "Bumi Sakti Alam Kerinci". Ini mengartikan daerah Kerinci merupakan daerah yang dikenal sakti, masih mempercayai nenek moyang walaupun telah hidup di zaman yang serba modern. Hal ini dapat dilihat dari kekentalan budaya masyarakat Kerinci dalam menjalankan adat istiadat daerahnya. Walaupun kaya akan alam dan budaya yang menarik, Kabupaten Kerinci ini tidak terdengar sebagai daerah wisata potensial. Yang paling kentara adalah kemerosotan jumlah kunjungan setiap tahunnya mencapai 24\% [10]. Semestinya dengan adanya pengembangan dan pengelolaan terarah, Kabupaten Kerinci dapat berkembang sebagai daerah pariwisata potensial di Sumatera[11].

\section{METODE PENCIPTAAN}

Metode penciptaan yang digunakan pada perancangan ini adalah dengan menggunakan metode 4D yang memiliki beberapa tahap dalam penciptaan sampai pada proses akhir yaitu penyebar luasan rancangan. Lalu juga menggunakan metode pengumpulan data berupa observasi ke lapangan, wawancara langsung dan pendokumentasian untuk menelaah apakah objek yang akan dirancang benar-benar dibutuhkan oleh pasar.

\section{Metode Perancangan 4D}

Penelitian ini menggunakan model pengembangan 4D (four-D). Model penelitian dan pengembangan 4D ini terdiri dari 4 tahapan, yaitu; define, design, develop, dan disseminate. Model pengembangan 4D diadaptasi menjadi; pendefinisian, perancangan, pengembangan, dan penyebaran.

2. Metode Pengumpulan Data

1. Observasi Lapangan

Melihat fenomena yang terjadi di lapangan mengharuskan penulis untuk langsung melakukan peninjauan secara cermat agar memahamai dan mengetahui secara benar dan faktual mengenai objek permasalahan yang diangkat.

2. Wawancara Langsung

Wawancara dengan berbagai sumber terkait dilakukan dalam bentuk pembuktian bahwa, fenomena dan persoalan yang sudah dipaparkan pada latar belakang masalah itu benar-benar terjadi, dan bukan pendapat subjektif dari penulis saja.

3. Dokumentasi

Dokumentasi bertujuan untuk memperoleh informasi yang mendukung analisis dan interpretasi data baik berupa dokumen dari arsip, buku dan website Dinas Pariwisata Kabupaten Kerinci. 
KREATIF(Jurnal Karya Tulis, Rupa, Eksperimental dan Inovatif)

Vol. 03 No. 01 Juni 2021

P-ISSN: 2746-4369 || E-ISSN: 2714-9978

\section{HASIL DAN PEMBAHASAN}

1. Hasil

Hasil Brand Visual Identity wisata cerdas Kabupaten Kerinci serta penerapannya pada media-media pendukung adalah sebagai berikut :

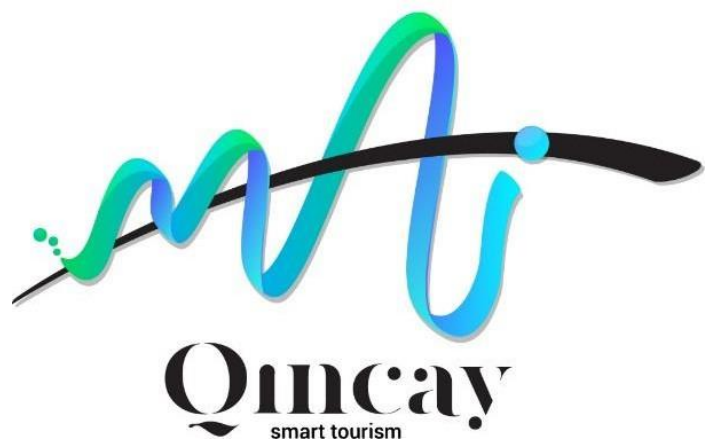

Gambar 1. Logo Mai Qincay Smart Tourism

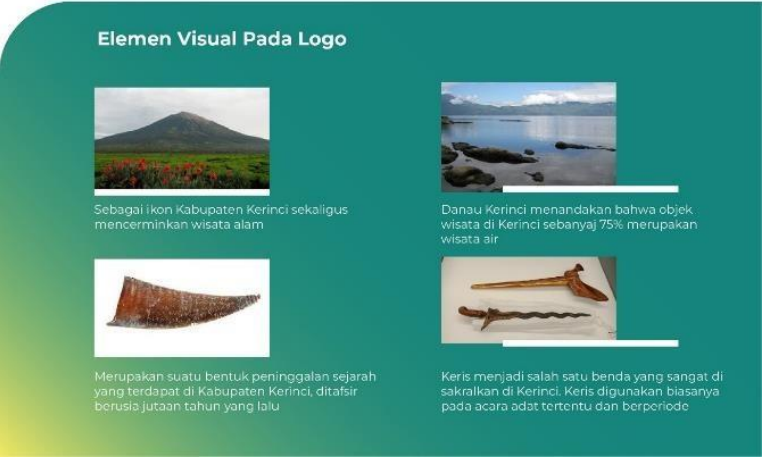

Gambar 2. Elemen-elemen Visual Yang Terkandung Dalam Logo

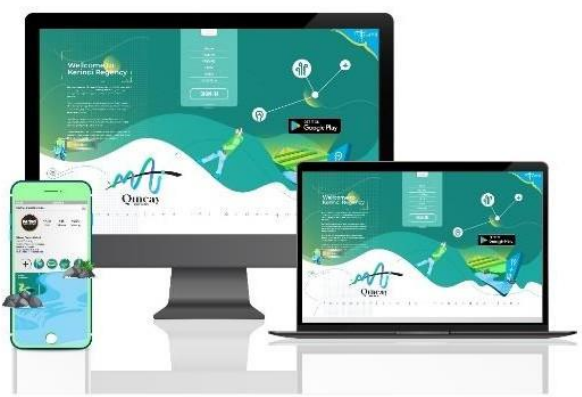

Gambar 3. Media Aplikasi pada Web, Aplikasi, dan Sosial Media

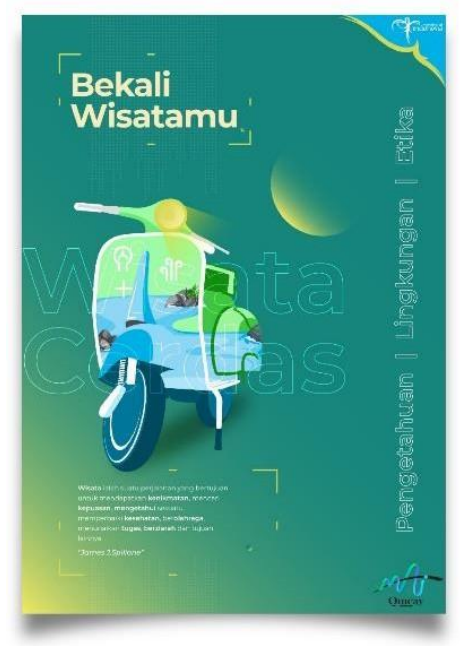

Gambar 4. Media Aplikasi Pada Media Luar Ruang Berupa Poster

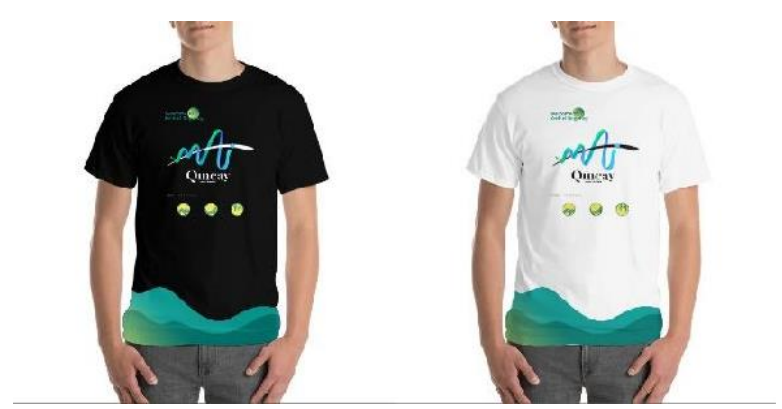

Gambar 5. Media Aplikasi Pada Merchandise T-shirt

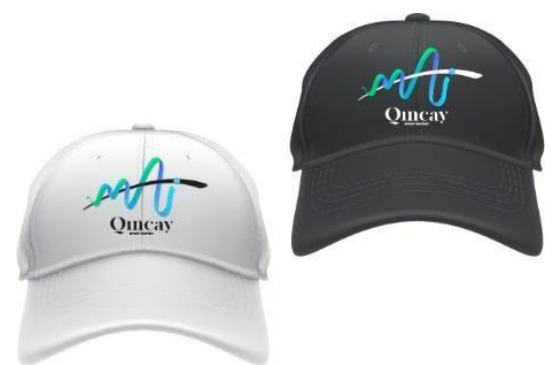

Gambar 6. Media Aplikasi Merchandise Sebagai Atribut Pariwisata 


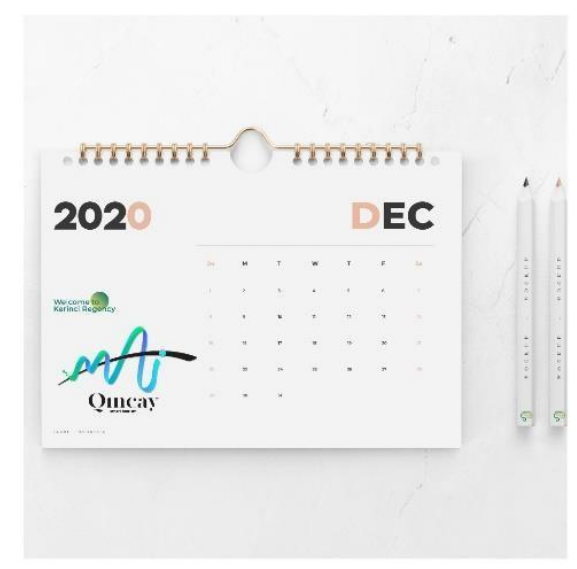

Gambar 7. Media Aplikasi Pada Media Kalender

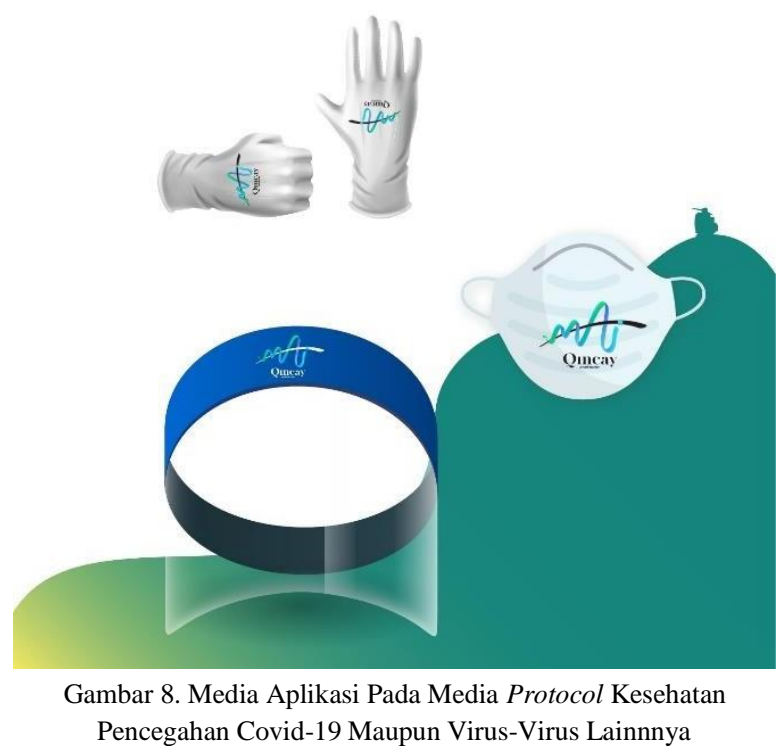

2. Pembahasan

Tahap awal dalam perancangan brand visual identity wisata cerdas Kabupaten Kerinci adalah dengan melakukan brainstorming yang digunakan untuk menelaah sejauh mungkin pokok persoalan yang dijumpai. Dalam mendesain sebuah brand visual identity sangatlah penting untuk melakukan karakter yang sesuai dengan ciri khas ke-pariwisataan Kabupaten Kerinci, agar citra dan identitas yang dibangun dapat dengan mudah dipahami oleh target sasaran.

\section{Konsep Verbal}

Perancangan Brand Visual Identity wisata cerdas Kabupaten Kerinci memiliki tahap pencarian brandname yang berkarakter. Adapun brandname yang dihasilkan adalah "Mai Qincay Smart Tourism". Dengan menggunakan Bahasa Daerah setempat diyakini bisa menjadi nilai jual karena menggunakan identitas lokal Kabupaten Kerinci sendiri. Setelah itu tagline berbahasa Inggris, hal ini guna memudahkan target sasaran secara global dalam memahami brand ini.

\section{Konsep Visual}

Visual yang menggambarkan karakter dari berbagai macam destinasi wisata yang terdapat di Kabupaten Kerinci, mulai dari wisata alam, wisata sejarah, wisata budaya, serta jenis-jenis pariwisata lainnya. Adapun ikon secara visual yang dihadirkan dalam logo "Mai Qincay" diatas adalah Gunung Kerinci, danau Kerinci, Aksara Incung, dan Keris.

Tahapan yang dilakukan dalam perancangan logo ini diawali dengan melakukan sketsa secara manual on paper, pewarnaan coloring, Alternatif, Studi Warna, dan finalisasi

\section{KESIMPULAN DAN SARAN}

1. Kesimpulan

Kesadaran masyarakat akan pentingnya berwisata secara cerdas di Kabupaten Kerinci memang harus ditanamkan mulai dari sekarang. Percepatan perkembangan zaman dan peningkatan teknologi sangat menunjang untuk hal itu. Perancangan Brand Visual Identity dapat meningkatkan popularitas Kabupaten Kerinci sebagai wilayah potensial pariwisata di masa depan. Hal ini tentu sangat bermanfaat bagi masyarakat agar terjadinya peningkatan perekonomian di Kabupaten Kerinci. Pemerintah pun juga akan sangat terbantu dalam hal pendistribusian produk-produk pariwisata di Kabupaten Kerinci.

2. Saran

Untuk mendukung upaya pengembangan pariwisata di Kabupaten Kerinci dibutuhkan saluran tangan dari berbagai pihak, salah satunya adalah Pemerintah. Agar perancangan ini dapat di finalisasi dan di realisasikan suatu saat nanti hendaknya. 
KREATIF(Jurnal Karya Tulis, Rupa, Eksperimental dan Inovatif)

Vol. 03 No. 01 Juni 2021

P-ISSN: 2746-4369 || E-ISSN: 2714-9978

\section{REFERENSI}

[1] CNN Indonesia (2018). www.cnnindonesia.com ; Kementerian Pariwisata Indonesia

[2] Casimeira Azita Yeja. 2016. Strategi Pengembangan Pariwisata Bumi Sakti Alam Kerinci Kabupaten Kerinci Provinsi Jambi. Kerinci : Jurnal Destinasi Pariwisata

[3] Frascara. 2004. Communication Design, Principles, Methods, and Practice, Allworth Press, New York

[4] Kusmiati A, Pudjiastuti (1999). Teori Dasar Komunikasi Visual. Jakarta: Djambatan

[5] Swasty, Wirania (2016). Branding : Memahami dan Merancang Strategi Merek. Bandung : PT. Remaja Rosdakarya.

[6] Rustan, Surianto. (2009). Mendesain Logo. Jakarta : PT. Gramedia Pustaka Umum

[7] Suwardikun. W, Didit. 2000. Merubah Citra Melalui Perubahan Logo. Bandung : ITB Library

[8] Rustan, Surianto. (2009). Mendesain Logo. Jakarta : PT. Gramedia Pustaka Umum

[9] Dewi, Ike Janita, Ph.D. 2011. Implementasi dan Implikasi Kelembagaan Pemasaran Pariwisata yang bertanggung jawab. Jakarta : Kementerian Kebudayaan dan Pariwisata Republik Indonesia

[10] Disporaparbud Kabupaten Kerinci. 2015. Kerinci Dalam Angka 2014. Kabupaten Kerinci

[11] Casimeira Azita Yeja. 2016. Strategi Pengembangan Pariwisata Bumi Sakti Alam Kerinci Kabupaten Kerinci Provinsi Jambi. Kerinci : Jurnal Destinasi Pariwisata 